\title{
EVALUATION OF THE REMAINING SHEAR CAPACITY IN CORRODED STEEL I-BEAMS
}

\author{
Y. Sharifi ${ }^{1, *}$ and R. Rahgozar ${ }^{1}$ \\ ${ }^{I}$ Civil Engineering Department, Kerman University, Kerman, Iran \\ *(Corresponding author: E-mail: yasser_sharifi@yahoo.com)
}

Received: 13 July 2009; Revised: 24 September 2009; Accepted: 30 November 2009

\begin{abstract}
There are a large number of steel structures subjected to corrosion due to environmental exposure; which results in reduction of its load carrying capacity. In this paper, thickness loss data were compiled from three samples of corrosion damaged I-beams, removed from a petrochemical industry. Common examples of corrosion that were found included damage loss of section in flanges and holes in the web which is likely to reduce the shear capacity significantly. The collected data was used to calculate the percentage of remaining shear capacity. Corrosion damaged model was developed for steel I-beams based on average measured thicknesses of corroded beams. Formulas were developed to relate the percentage of remaining shear capacity to percentage thickness loss of the corrosion damaged I-beam. It will be shown that very few approximations were needed to derive these analytical relations. The effects of corrosion on steel beams are analyzed by evaluating the remaining capacity with regard to shear failure. Hence, the results of this study can be used for better prediction of the service life for deteriorating steel beams.
\end{abstract}

Keywords: Corrosion; steel beams; damaged model; remaining shear capacity

\section{INTRODUCTION}

Steel structures such as ships, offshore platforms and land-based structures are prone to various types of damage as they get older. Corrosion and fatigue cracking may be the two most important types of damage in aging structures (Paik et al. [1-2]).

Nakai et al. [3] studied that corrosion is an unavoidable phenomenon in steel structures and thickness loss of the structural members due to corrosion is a great concern when the integrity of structures is considered. Concepts of 'corrosion margin' and 'allowable corrosion level' have been introduced conventionally to cope with this problem. The corrosion margin is an additional thickness at the design stage and the allowable corrosion level is used as a guide to determine when to renew worn members at the maintenance stage.

Corrosion is the major cause of deterioration in steel structures. Results of this deterioration can range from progressive weakening of the steel structure over a long period of time to sudden collapse of the structure. The effects of corrosion damage vary with the type of structure, the location and extent of deterioration. Corrosion damage must be carefully appraised and evaluated. In some cases, immediate repair or closure is necessary while in other cases, the conditions created by corrosion can be tolerated. In all cases, however, the likely progression of corrosion must be considered (Kulicki et al. [4]).

The main effects of corrosion on steel structures can be loss of material from the surface which leads to thinner sections (Figure 1). The section properties of a member, such as, area, second moment of area, radius of gyration, etc., would be reduced due to loss of material, thus causing a reduction in carrying capacity of the structure. Corrosion can lead to cracking (fracture), yielding or bucking of members. This can result in stress concentration, changes in geometric parameters, and a build-up of the corrosion products. These parameters are critical for the member's ability to resist load effects (Czarnecki and Nowak [5]). It has been pointed out by Kayser and Nowak [6] that the stiffness of members may also be reduced from loss of material, which may cause excessive deflections. 
The most important form of corrosion is a general loss of surface material; this condition will lead to the gradual thinning of members. General corrosion accounts for the largest percentage of corrosion damage (Kayser [7]). The corrosion of metal has been intensively studied since the 1940's. A large amount of data has been collected on the rate of material loss in metal specimens under different environmental conditions. Corrosion test results on loss of materials for various environments (urban, rural and marine) have been summarized by Albrecht and Naeemi [8]. Loss of material may affect any one of the three modes of resistance in a steel I-beam i. e. bending, shear and bearing. Loss of flange material causes a reduction in the net area available to resist bending. Furthermore, the moment of inertia will be reduced, causing an increase in deflection. Also, the ultimate bending strength will be reduced, causing a reduction in maximum carrying capacity (Rahgozar [9]).

It is possible to establish a relationship between the remaining capacities of various failure modes (moment, shear, bearing ...) and the loss of thickness for a given member. This approach can form the basis for establishing a quantitative relationship between the magnitude of corrosion defects and the corresponding remaining capacity. The corrosion decay model, namely uniform thickness loss model is developed in this study and will be used for the development of assessment method. For a particular failure mode of a beam, if the percentage remaining capacity is plotted against the percentage loss of thickness, we will obtain a curve that gives the relationship between them (Rahgozar [10]; Sharifi and Rahgozar [11]).

The effect of corrosion on structural strength is not yet clear. Further investigation is necessary to clarify how the corrosion affects strength of hold frames as beams. When beam strength is considered, (1) collapse strength (no buckling), (2) lateral-distortional buckling strength, (3) local buckling strength, (4) shear strength of web plates and (5) web crippling strength under concentrated loading etc. are important factors (Nethercot [12]). Furthermore, in this paper universal I-beams with uniform corrosion were used to calculate their remaining shear capacities. The results of this study can be used for a better prediction of the service life (remaining shear capacity) of deteriorating I-beams.

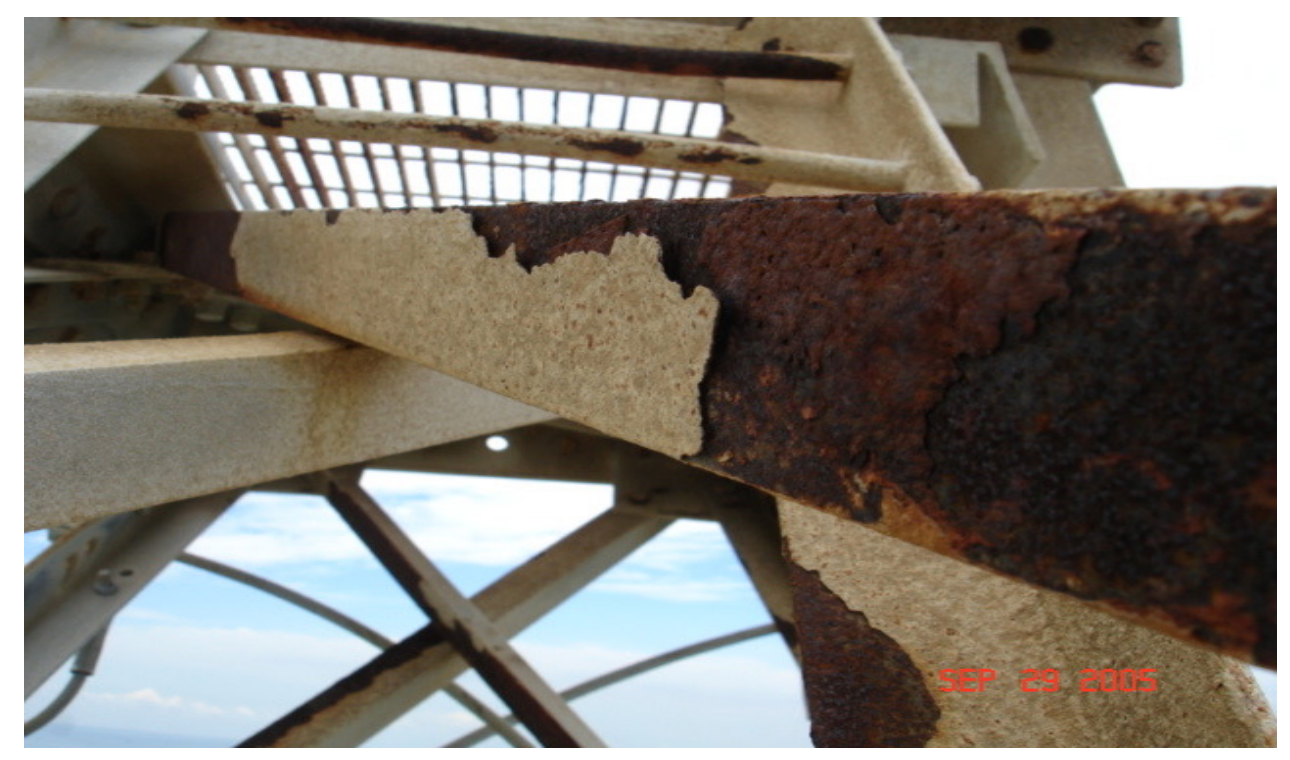

Figure 1. Loss of Material from the Surface of a Steel Beam Due to Corrosion 


\section{ANALYSIS OF THE EFFECT OF CORROSION DAMAGE IN STEEL BEAMS}

Development of corrosion decay models requires the information on locations where corrosion normally occurs and the types of corrosion damage in steel members. The most common form of corrosion damage in steel is the general surface corrosion. Uniform corrosion is the formation of oxide distributed uniformly over an exposed surface (Figure 1). This is the most common form of the corrosion, which leads to gradual thinning of members; and accounts for the greatest amount destruction in metals (Fontana [13]). General corrosion is the most serious form of corrosion observed on steel bridges (Kayser and Nowak [14]). Here a corrosion decay model was considered by reducing thickness of the sections. The model which is shown in Figure 2 is the uniform thickness loss in both flanges and web (Rahgozar [9]).

The corrosion decay model developed for the uniform thickness loss model sections with some modifications is as follows:

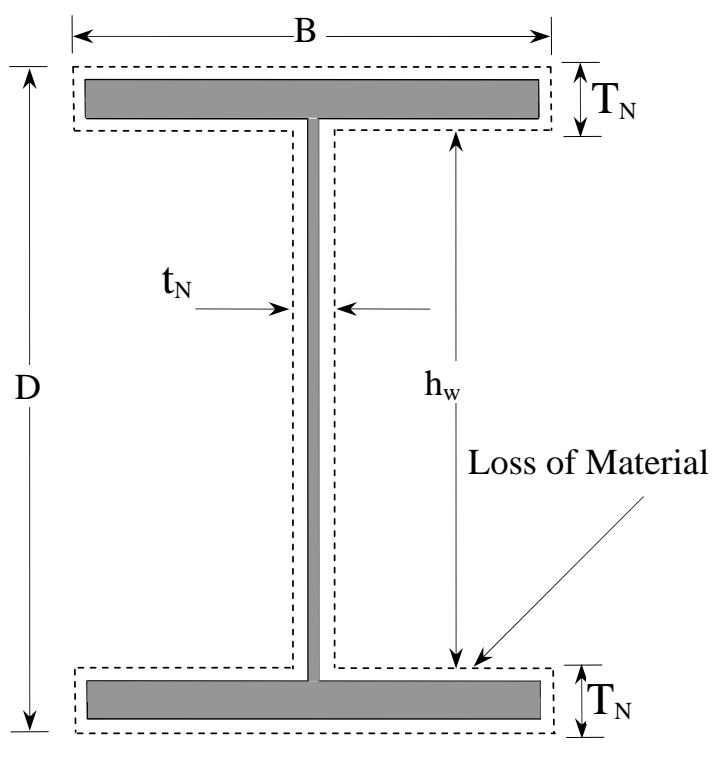

\section{Loss of Material}

Flanges $\quad \mu T_{N}$

Web $\quad \mu t_{N}$

Where

$T_{N}$ Thickness of the flange of as new section

$t_{N}$ Thickness of the web of as new section

$\mu=\% L F T / 100=\% L W T / 100$

$\% L F T=$ Percentage loss of flange thickness

$\% L W T=$ Percentage loss of web thickness

Figure 2. Uniform Thickness Loss Model

Thickness of the top flange $=T_{N}(1-\mu)$

Thickness of the bottom flange $=T_{N}(1-\mu)$

Average thickness of the flanges, $T_{C}=T_{N}(1-\mu)$

Thickness of the web, $t_{c}=t_{N}(1-\mu)$

Where

$\mu=\mu_{F}=\mu_{W}$,

$\mu_{F}=\% L F T / 100$,

$\mu_{W}=\% L W T / 100$,

\section{SHEAR CAPACITY}

The web panel shown in Figure 3(a) is loaded in shear and the web is stiffened using stiffeners of length $a_{s}$. The thin flat plate of length, $a_{s}$, depth $d$, and thickness $t$ shown in Figure 3(b) is simply supported along all four edges. The plate is loaded in shear, distributed uniformly along its edges. When these stresses are equal to the elastic buckling value, $\tau_{c r}$, then the plate will buckle laterally out of its original plane into an adjacent position (Trahair et al. [15]). The elastic critical shear stress $\tau_{c r}$, at which the web buckles can be predicated from plate buckling theory and is given by Timoshenko and Gere [16] as: 
$\tau_{c r}=k \frac{\pi^{2} E}{12\left(1-v^{2}\right)(d / t)^{2}}$

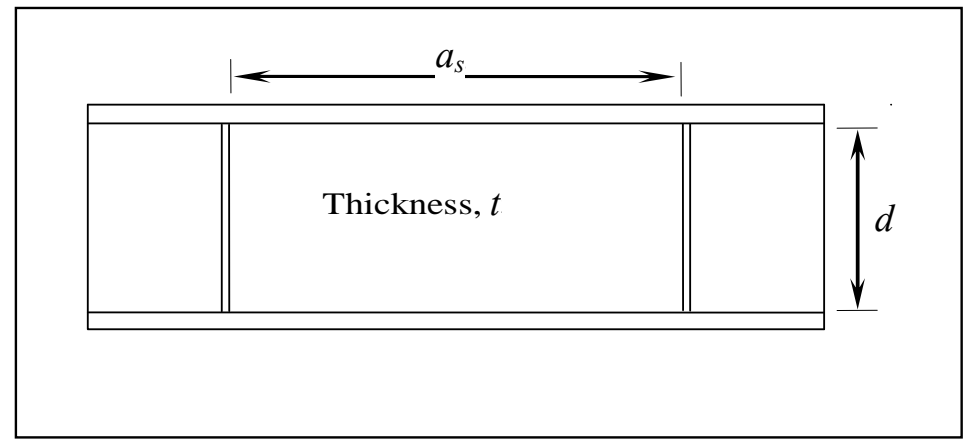

(a) Geometry of Web Panel

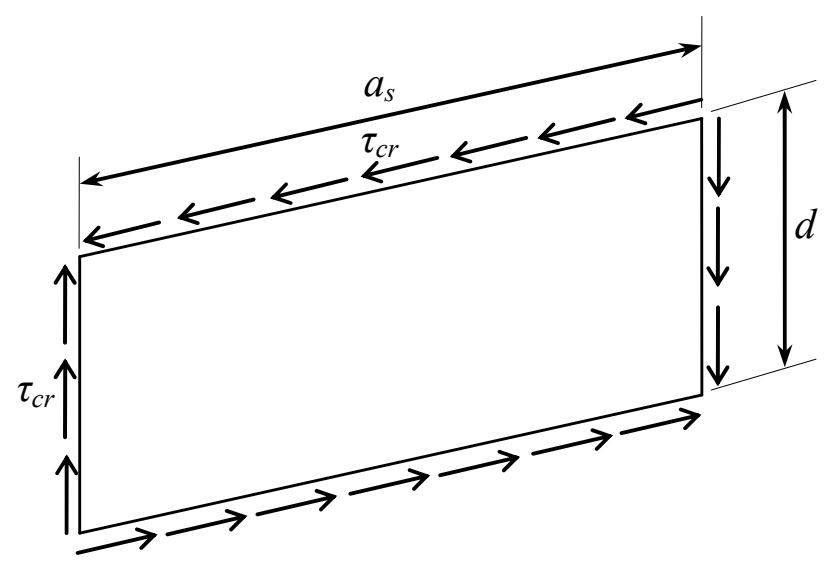

(b) Buckled Pattern of a Simply Supported Plate in Shear

Figure 3. Web Buckling Due to Pure Shear

In which the buckling coefficient, $k$ is determined by a theoretical critical load analysis (Timoshenko and Gere [16]; Stowell et al. [17]). It is a function of plate geometry and boundary conditions and is given by Johnston [18] as:

$k=4.00+\frac{5.34}{\left(a_{s} / d\right)^{2}} \quad$ for $a_{s} / d \leq 1$

$k=5.34+\frac{4.00}{\left(a_{s} / d\right)^{2}} \quad$ for $a_{s} / d \geq 1$

If the numerical values for $v=0.3$ and $E=205000 \mathrm{~N} / \mathrm{mm}^{2}$ are substituted in to Eq. 2, and further combined with Eqs. 3a and 3b, then,

$\tau_{c r}=\left(0.75+\frac{1.00}{\left(a_{s} / d\right)^{2}}\right)\left(\frac{995}{d / t}\right)^{2} \quad$ for $a_{s} / d \leq 1$ 


$$
\tau_{c r}=\left(1.00+\frac{0.75}{\left(a_{s} / d\right)^{2}}\right)\left(\frac{995}{d / t}\right)^{2} \quad \text { for } a_{s} / d \geq 1
$$

The shear stresses in many structural members are transmitted by unstiffened webs, for which the aspect ratio, $a / d$, is large and assumed infinity. Therefore, for unstiffened webs, using Eq. $4 \mathrm{~b}, \tau_{c r}$ can be given as:

$$
\tau_{c r}=\left(\frac{995}{d / t}\right)^{2}
$$

Using maximum distortion strain energy theory (Von-Mises yield criterion); it can be shown that the yield stress in shear, $\tau_{y}$, is equal to $p_{y w} / \sqrt{3}\left(\approx 0.6 p_{y w}\right)$, where $p_{y w}$ is the design strength of the web (Trahair et al. [15]). Stocky unstiffened webs in steel beam yield in shear before they buckle elastically. When a web panel yields, the critical shear stress is equal to the yield stress in shear.

i.e. $\tau_{c r}=\frac{p_{y w}}{\sqrt{3}}$

Using Eqs. 5 and 6, the limiting ratio of $d / t$ for web yielding in shear can be given as:

$d / t=79 \varepsilon$

where

$$
\varepsilon=\sqrt{275 / p_{y w}}
$$

A stocky unstiffened web in an I-section beam subjected to pure shear loading is shown in Figure 4(a). The web behaves elastically in shear until yielding starts at $\tau_{y}=p_{y w} / \sqrt{3}$, yielding continues as the section undergoes increasing plastification until the web has yielded fully in shear (Figure 4(b)). Because the shear stress distribution at first yield is nearly uniform, the nominal first yield and fully plastic loads are nearly equal, and the shear shape factor is usually very close to 1.0. Stocky unstiffened webs in steel beams reach first yield before they buckle elastically, hence their strengths are determined by the shear stress $\tau_{y}$, as indicated in Figure 4.

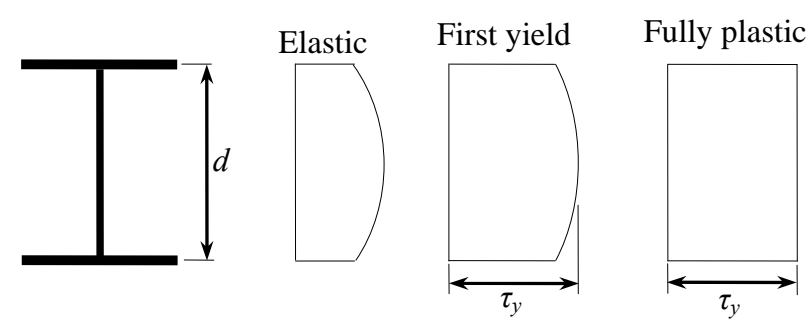

$\begin{array}{ll}\text { (a) I-section } & \text { (b) Shear stress distributions }\end{array}$

Figure 4. Plastification of an I-Section Web in Shear

Thus the resistance of a stocky web in a flanged section for which the shear shape factor is near unity is closely approximated by the web plastic shear resistance: 
$V_{w}=d t \tau_{y}$

When the depth to thickness ratio $d / t$ of a long unstiffened steel web exceeds $79 \sqrt{275 / p_{y w}}$, its elastic buckling shear stress $\tau_{c r}$, is less than the shear yield stress.

The design shear force $F_{v}$ on a web for which the shear stress is approximately uniform must satisfy $F_{v} \leq P_{v}$, in which $P_{v}$ is the uniform shear capacity. The uniform shear capacity of a stocky web of area $A_{v}$ is given by:

$P_{v}=0.6 p_{y} A_{v}$

Which is very close to $d t \tau_{y}\left(\approx 0.58 A_{v} p_{y}\right)$ given for the fully plastic shear capacity. I-section web is classified by BS 5950 as stocky when its depth to thickness ratio satisfies $d /(t \varepsilon) \leq 70$ for a hot-rolled beam (the web of all British universal sections of S275 or S355 steel are stocky), and when $d /(t \varepsilon) \leq 62$ for a welded plate girder, otherwise it is classified as slender. Note that the value 62 is less than the value of 79 used in previous section on limiting slenderness when elastic buckling $\tau_{c r}$ is equal to shear yield stress $\tau_{y}$ (Trahair et al. [15]).

BS 5950 recommends that when $d / t$ exceeds $62 \varepsilon$ the web should be checked for signs of shear buckling. This limiting value of $d / t$ is based on the experimental work by Horne [20]. The code uses notation $q_{e}$ instead of $\tau_{c r}$ for the elastic critical shear stress. It also identifies three modes of behavior for webs.

The first mode is where the web strength is governed by its ultimate yield strength, i.e. $p_{y w} / \sqrt{3}$, the third is where the capacity is solely governed by the elastic critical shear stress, $q_{c r}$, and the intermediate stage is where an interaction occurs between the first and third modes. The divisions between the three modes are quantified by equivalent web slenderness factor, $\lambda_{w}$, which is given by (Trahair et al. [15]):

$\lambda_{w}=\left(p_{v} / q_{e}\right)^{0.5}$

where

$p_{v}=0.6 p_{y w}$

Code (BS 5950) gives the critical shear strength, $q_{w}$, of a web panel as follows:

For $\lambda_{w} \leq 0.8, q_{w}=p_{v}$

For $0.8<\lambda_{w}<1.25, q_{w}=\left[\left(13.48-5.6 \lambda_{w}\right) / 9\right] p_{v}$

For $\lambda_{w} \geq 1.25, q_{w}=\left(0.9 / \lambda_{\mathrm{w}}\right) p_{v}$

when no stiffener is provided, using Eqs. 5 and 11 it can be shown that,

For $\lambda_{w}=0.8$, then $d / t=62 \varepsilon$

For $\lambda_{w}=1.25$, then $d / t=97 \varepsilon$ 
When an I-beam is subjected to bending, most of the applied shear force is resisted by the web. Web thickness of a corroded beam can remain uniform at initial stages of corrosion. In sections, where web thickness does not vary significantly due to corrosion, average web thickness may be used for evaluating the shear capacity. Under these circumstances shear capacity can be evaluated in accordance with BS 5950 [19]. When depth to thickness ratio, $d / t$, exceeds $62 \varepsilon$ the web should be checked for shear buckling in accordance with BS 5950 [19].

\section{ASSESSMENT METHOD FOR ESTIMATING THE REMAINING SHEAR CAPACITY IN CORRODED STEEL I-BEAMS}

Corrosion in web and flanges leads to reduction in shear capacity. In addition, class of a section may be changed from one into another. This may change this failure mode from plastic yielding to shear buckling. If the web of a corrosion damaged beam varies in thickness significantly, the shear capacity should be calculated from first principles assuming elastic behavior. In sections where the variation in web thickness due to corrosion is small, average web thickness may be used for evaluating the shear capacity. The theory given in Section 3 was used in evaluation of remaining shear capacity in corrosion damaged beams.

Taking into account that corrosion may change the class of a section, three categories of sections in terms of $d / t$ ratio are considered for the development of assessment methods for remaining shear capacity. The three categories are given below.

\section{Category 1}

$d / t \leq 62 \varepsilon \rightarrow q_{w}=p_{v}$

2. Category 2

$62 \varepsilon<d / t<98 \varepsilon \rightarrow q_{w}=\left[\left(13.48-5.6 \lambda_{w}\right) / 9\right] p_{v}$

3. Category 3

$d / t \geq 98 \varepsilon \rightarrow q_{w}=\left(0.9 / \lambda_{\mathrm{w}}\right) p_{v}$

Now the objective is to generate minimum curves for estimating the percentage remaining shear capacity (\%RSC) of corrosion damaged beams. These minimum curves can be obtained by identifying the worst case scenario.

\subsection{Categories of Sections Unchanged By Corrosion}

\subsubsection{Category 1: $d / t \leq 62 \varepsilon$}

Although corrosion reduces thickness of a web, some sections of this category that have the lowest $d / t$ ratio in their as-new condition may remain in the same category even after being damaged by corrosion. For Category 1 sections, the shear capacity, $P_{v}$, is given by:

$P_{v C}=p_{v} A_{v C} \quad$ for corrosion damaged sections

$P_{v N}=p_{v} A_{v N} \quad$ for as-new sections

where $A_{v}$ is the shear area taken as follows:

$A_{V}=D t \quad$ for rolled I-sections

$A_{v}=d t \quad$ for welded I-sections. 
In which, $D$ is beam's depth and $d$ is the clearing distance between flanges

The percentage remaining shear capacity $(\% R S C)$ of any corrosion damaged beam, which is the ratio of the capacity of corrosion damaged beam $\left(P_{v C}\right)$ to the capacity of as- new beam $\left(P_{v N}\right)$ may be expressed as:

$$
\begin{aligned}
& \% R S C=100\left(P_{v C} / P_{v N}\right) \\
& \% R S C=100\left(\frac{t_{C}}{t_{N}}\right)
\end{aligned}
$$

where

$t_{N}$ is web thickness of the beam in its as-new condition and

$t_{C}$ is web thickness of the corrosion damaged beam

It should be noted from Eq. 19 that design strength of the material has no effect on $\% R S C$ in Category 1 sections. The relation for \%RSC (Eq. 19) may be written as follows.

$$
\begin{aligned}
& \% R S C=100\left(1-\frac{t_{N}-t_{C}}{t_{N}}\right) \\
& \% R S C=100\left(1-\mu_{w}\right)
\end{aligned}
$$

where

$\mu_{W}=\% L W T / 100$, and

$\% L W T$ is the percentage loss in web thickness.

The $\% R S C$ (Eq. 21) is a function of $\mu_{w}$ alone. Therefore, Eq. 21 may be used as the minimum curve for estimating the \%RSC of any corrosion damaged sections that are category 1 in both as-new and corrosion damaged conditions. The estimates from the above equation will be almost exact for all the available I-sections.

\subsubsection{Category 2: $62 \varepsilon<d / t<98 \varepsilon$}

Although corrosion reduces the thickness of a web, some sections that fall into Category 2 in their as new- condition may remain unchanging in part or their entire service life. For such sections, the shear capacity, $P_{v}$, is given by:

$P_{v C}=p_{v} \phi_{C} A_{v C}$ for corrosion damaged sections

$P_{v N}=p_{v} \phi_{N} A_{v N}$ for as-new sections

where

$$
\phi=\left[1.5-0.62 \lambda_{w}\right]
$$

and $A_{v}$ is as described in Section 4. 1.1

If it is assumed that the depths, $D$ and $d$, of the corrosion damaged sections remain constant throughout their service life and the Eqs. 22a and 22b are combined with Eq. 18, then the $\% R S C$ of Category 2 sections is: 
$\% R S C=100\left(\frac{\phi_{C}}{\phi_{N}}\right)\left(\frac{t_{C}}{t_{N}}\right)$

Alternatively, using Eq. 21, the above equation can be modified to give,

$\% R S C=100\left(\frac{\phi_{C}}{\phi_{N}}\right)\left(1-\mu_{w}\right)$

In this case the $\% R S C$ depends on both $\mu_{w}$ and the ratio $\phi_{C} / \phi_{N}$. In order to obtain the minimum of $\% R S C$ given by Eq. 25, the minimum of the ratio $\phi_{C} / \phi_{N}$ must be obtained. Using Eq. 23, the ratio $\phi_{C} / \phi_{N}$ may be written as:

$$
\frac{\phi_{C}}{\phi_{N}}=\frac{1.5-0.62 \lambda_{w C}}{1.5-0.62 \lambda_{w N}}
$$

where, $\lambda_{w}$ is the web slenderness factor (see Section 4) and is given by:

$\lambda_{w}=\left(\frac{p_{v}}{q_{e}}\right)^{0.5}=\frac{p_{v}^{0.5}}{995.0} \frac{d}{t}=\frac{\left(0.6 p_{y w}\right)^{0.5}}{995.0} \frac{d}{t}$

Assuming that $d$ is constant, substituting Eq. 1b into Eq. 27a gives,

$$
\lambda_{w C}=\frac{p_{v}{ }^{0.5}}{995.0} \frac{d}{t_{C}}=\frac{p_{v}{ }^{0.5}}{995.0} \frac{d}{t_{N}\left(1-\mu_{w}\right)}=\frac{\lambda_{w N}}{1-\mu_{w}}
$$

Now, substituting Eq. 27b into Eq. 26, gives the following expression for the ratio $\phi_{C} / \phi_{N}$ :

$$
\frac{\phi_{C}}{\phi_{N}}=\frac{\frac{2.42}{\lambda_{w N}}-\frac{1}{1-\mu_{w}}}{\frac{2.42}{\lambda_{w N}}-1}
$$

Eq. 28 demonstrates that for a given value of $\mu_{w}$, when the value of $\lambda_{w N}$ increases, the value of $\phi_{C} / \phi_{N}$ decreases. Hence, for the minimum value of $\phi_{C} / \phi_{N}, \lambda_{w N}$ must be the maximum obtainable from the maximum values of $p_{y}$ and $d / t_{N}$ (see Eq. 27a). The possible maximum values of $p_{y}$ and $d / t_{N}$ of Category 2 sections are:

$\operatorname{Max}\left(p_{y}\right)=450 \mathrm{~N} / \mathrm{mm}^{2}$ and

$\operatorname{Max}\left(d / t_{N}\right)=60.33 \quad$ for section $U B 44(406 \times 140 U B 39)$

If the above maximum values are substituted into Eq. 27a, then the maximum value of $\lambda_{w N}$ is:

$\operatorname{Max}\left(\lambda_{w N}\right)=0.996$ 
Combining 28 and 29 gives the minimum of $\phi_{C} / \phi_{N}$ as:

$\operatorname{Min}\left(\frac{\phi_{C}}{\phi_{N}}\right)=1.7-\frac{0.7}{1-\mu_{w}}$

Now, if Eqs. 25 and 30 are combined, the following relation is obtained for the minimum $\% R S C$ for Category 2 sections,

$\operatorname{Min}(\% R S C)=100\left(1-1.7 \mu_{w}\right)$

Therefore, Eq. 31 may be used as the minimum curve to estimate the \%RSC of any corrosion damaged sections that are Category 2 in their as-new condition and remain in this category even in their corroded states. The estimates will be conservative for some sections since Eq. 31 was derived for the worst combinations of $p_{y}$ and $d / t$.

\subsubsection{Category 3: $d / t \geq 98 \varepsilon$}

Plate girders that have the highest value of $d / t$ may fall into Category 3 in their as-new condition. For Category 3 beams, the shear buckling capacity, $P_{v}$, is given by:

$P_{v C}=\left(0.9 / \lambda_{w C}\right) p_{v} A_{v C} \quad$ for corrosion damaged section

$P_{v N}=\left(0.9 / \lambda_{w N}\right) p_{v} A_{v N}$ for as-new sections

If Eqs. 32a and 32b are combined with Eq. 18, and then the $\% R S C$ of Category 2 sections is obtained as:

$\% R S C=100\left(\frac{\lambda_{w N}}{\lambda_{w C}}\right)\left(\frac{t_{C}}{t_{N}}\right)=100\left(\frac{\lambda_{w N}}{\lambda_{w C}}\right)\left(1-\mu_{w}\right)$

Assuming that the beam depth, $d$, remains constant for all of its service life, combining Eq. 27b with Eq. 33 gives the $\% R S C$ of Category 3 beams as:

$\% R S C=100\left(1-\mu_{w}\right)^{2}$

The $\% R S C$ of Category 3 sections are a function of $\mu_{w}$ alone. Therefore, Eq. 34 may be used as the minimum curve for estimating the $\% R S C$ of any corrosion damaged section that is Category 3 in both as-new and corrosion damaged conditions. The above equation will give almost exact estimates of the $\% R S C$ for all such sections.

\subsection{Category of Section Changed By Corrosion}

\subsubsection{Category 1 to Category 2 to Category 3}

Some sections that are of Category 1 in their as-new condition may become Category 2 and then Category 3 during their service life due to loss of thickness in the web. When sections are of Category 1, Eq. 21 may be used as the minimum curve for estimating the $\% R S C$ as suggested before. Let us first consider the case in which the sections become Category 2 due to corrosion. When a section's category is changed from 1 to 2 the $\% R S C$ of such section may be obtained by combining Eqs. 13, 16b and 22a to yield: 
$\% R S C=100 \phi_{C}\left(1-\mu_{w}\right)$

where

$\phi_{C}=\left[1.5-0.62 \lambda_{w C}\right]$

To obtain the minimum of $\% R S C$ in Eq. 35, the minimum of $\phi_{C}$ must be found first. Combining Eq. 27b and 36 yields,

$\phi_{C}=1.5-\frac{0.62 \lambda_{w N}}{1-\mu_{w}}$

For a given $\mu_{w}$ the minimum value of $\phi_{C}$ can be obtained for the maximum value of $\lambda_{w N}$. As in Section 4.1.2, the maximum value of $\lambda_{w N}$ is obtained from the maximum values of $p_{y}$ and $d / t_{N}$ for a section that is of Category 1 in as-new condition; i. e.

$\operatorname{Max}\left(p_{y}\right)=344 \mathrm{~N} / \mathrm{mm}^{2} \quad$ and

$\operatorname{Max}\left(d / t_{N}\right)=60.33$ for section UB 44

Note: If $p_{y}>344 \mathrm{~N} / \mathrm{mm}^{2}$, then section $U B 44$, is of Category 2 in its as new condition

Using this data, maximum value of $\lambda_{w N}$ is obtained as:

$\operatorname{Max}\left(\lambda_{w N}\right)=0.82$

Substituting Eq. 38 into Eq. 37 gives the minimum of $\phi_{C}$ as:

$\operatorname{Min}\left(\phi_{C}\right)=1.5-\frac{0.511}{1-\mu_{w}}$

Now, if Eqs. 35 and 39 are combined, then the following relation is obtained for the minimum of $\% R S C$ for sections of category 2 that were originally of Category 1 in their as-new condition,

$\operatorname{Min}(\% R S C)=100\left(1-1.5 \mu_{w}\right)$

Hence, when a corrosion damaged section is of Category 1 in its as-new condition and becomes of Category 2, Eq. 40 may be used for estimating the \%RSC. This equation will give conservative estimates for some sections since it was derived for the worst combinations of $p_{y}$ and $d / t$ ratio.

Now, let us consider the case in which the sections become Category 3 due to corrosion. When they become Category3, using Eqs. 16b and 32a together with Eq. 18, the $\% R S C$ may be given as:

$\% R S C=\frac{90}{\lambda_{w N}}\left(1-\mu_{w}\right)^{2}$

For the minimum value of $\% R S C$ in Eq. $41, \lambda_{w N}$ must be maximum. The maximum value of $\lambda_{w N}$ was obtained as 0.82 (see Eq. 38). Hence, the minimum $\% R S C$ in sections of Category 3 that were of Category 1 in their as-new condition is obtained as: 


$$
\operatorname{Min}(\% R S C)=110\left(1-\mu_{w}\right)^{2}
$$

Therefore, when a corrosion damaged section is of Category 1 in its as-new condition becomes Category 3, Eq. 42 may be used as the minimum curve for estimating the $\% R S C$. As Eq. 42 was derived for the worst combinations of $P_{y}$ and $d / t$, the estimates will be conservative for some sections.

\subsubsection{Category 2 to Category 3}

Some sections that are of Category 2 in their as-new condition may become Category 3 due to loss of thickness in the web. When corrosion damaged sections are Category 2, Eq. 31 may be used as the minimum curve for estimating the $\% R S C$ as before. When they become Category 3 , substituting Eqs. 22b and 32a into Eq. 18, gives the \%RSC as:

$\% R S C=\frac{90}{\lambda_{w N} \phi_{N}}\left(1-\mu_{w}\right)^{2}$

where the term $\lambda_{w N} \phi_{N}$ may be given by:

$$
\lambda_{w N} \phi_{N}=\lambda_{w N}\left[1.5-0.62 \lambda_{w N}\right]
$$

In order to obtain the minimum $\% R S C$ from Eq. 43, maximum value of $\lambda_{w N} \phi_{N}$ must be used. Eq. 44 shows that when value of $\lambda_{w N}$ increases, value of $\lambda_{w N} \phi_{N}$ also increases. For sections of category 2 in their as-new condition, maximum value of $\lambda_{w N}=0.996$ (see Eq. 29), hence, maximum value of $\lambda_{w N} \phi_{N}$ is:

$$
\operatorname{Max}\left(\lambda_{w N} \phi_{N}\right)=0.879
$$

Now, substituting Eq. 45 into Eq. 43 yields the minimum \%RSC in sections of Category 3 that was originally of Category 2 in their as new condition i. e.:

$$
\operatorname{Min}(\% R S C)=102.4\left(1-\mu_{w}\right)^{2}
$$

Therefore, when corrosion damaged section that is of Category 2 in its as-new condition becomes Category 3; Eq. 46 can be used as the minimum curve for estimating the $\% R S C$. Estimates will be conservative for some sections, as Eq. 46 was obtained for the worst possible case.

\section{MINIMUM CURVES FOR THE UNIFORM THICKNESS LOSS MODEL SECTIONS}

Corrosion discovered model for the uniform thickness loss model is developed for steel I-beams. It was found that a relationship between the remaining shear capacity and the loss of thickness for an I-beam section can be established and for a given category, if the percentage remaining shear capacity is plotted against the percentage loss of thickness; and the resulting curve establishes their relationship. Since these curves are obtained by identifying the worst case scenarios, they yield 
conservative estimates and hence can be taken as minimum curves. The suggested minimum curves can be compared with the failure loads of three samples of corrosion damaged beams. The beams were tested individually for their ultimate failure (shear capacity) load in the laboratory (Rahgozar [9]).

Based on analytical findings, minimum curves were established and are given in Figure 5 for the following cases:

A. Sections that are of Category 2 in both their as-new and corrosion damaged conditions (C1)

B. Sections that are of Category 2 in both their as-new and corrosion damaged conditions (C2)

C. Sections that are of Category 2 in both their as-new and corrosion damaged conditions (C3)

D. Sections that are Category 1 in their as-new condition and become Category 2 and then Category 3 due to corrosion (C1 to C3)

E. Sections that are Category 1 in their as-new condition and become Category 2 during their service life (C1 to C2)

F. Sections that are Category 2 in their as-new condition and become Category 3 during their service life (C2 to C3).

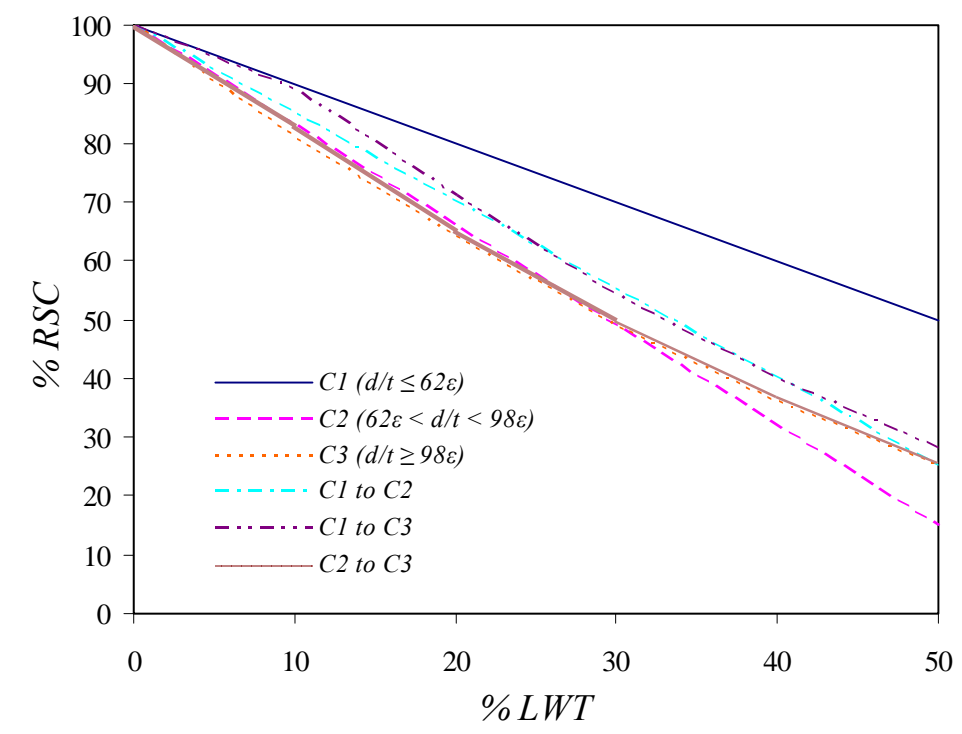

Figure 5. Minimum Curves for Estimating the $\% R S C$ of

Corrosion Damaged Beams with Uniform Thickness Loss

\section{CONCLUSIONS}

In this paper a method has been proposed to asses the remaining shear capacity of corrosion damaged I-beams. The proposed methodology yields a quantitative relationship between the magnitude of structural defects and the corresponding remaining shear capacity in corrosion damaged beams. Here, it was discovered that estimates of the remaining shear capacity of corrosion damaged beams are almost exact. Furthermore, this methodology is easy to use and does not require lengthy calculations. In particular, equations obtained in this assessment method will be more effective in assessing the capacity of corrosion damaged I-beams. Realistic appraisal of the capacity of corrosion damaged beams by this method will avoid premature plant closures. In addition, this method may be used to identify the weaker members whose capacities are closer to the service loads. This assessment method will help practicing engineers to make a fast and reliable decision regarding the future of their corrosion damaged I-beam. For all practical purposes, the proposed minimum curves can be used along with the information on the material loss to estimate the percentage remaining shear capacity of corrosion damaged beams. 


\section{REFERENCES}

[1] Paik, J.K., Lee, J.M. and Ko, M.J., "Ultimate Compressive Strength of Plate Elements with Pit Corrosion Wastage”, Journal of Engineering Maritime Environmental, 2003, Vol. 217, No. M4, pp. 185-200.

[2] Paik, J.K., Lee, J.M. and Ko, M.J., "Ultimate Shear Strength of Plate Elements with Pit Corrosion Wastage”, Thin-Walled Structures, 2004, Vol. 42, pp. 1161-76.

[3] Nakai, T., Matsushita, H. and Yamamoto, N., "Effect of Pitting Corrosion on Strength of Web Plates Subjected to Patch Loading”, Thin-Walled Structures, 2006, 44, pp. 10-19.

[4] Kulicki, J.M., Prucs, Z., Sorgenfrei, D.F. and Mertz, D.R., "Guidelines for Evaluating Corrosion Effects in Existing Steel Bridges", National Cooperative Highway Research Program, Report 333, Transportation Research Board, National Research Council, Washington, D.C; 1990.

[5] Czarnecki, A.A. and Nowak, A.S., "Time-Variant Reliability Profiles for Steel Girder Bridges”, Structural Safety, Elsevier, 2008, Vol. 30, pp. 49-64.

[6] Kayser, J.R. and Nowak, A.S., "Capacity Loss Due to Corrosion in Steel-Girder Bridges”, Journal of Structural Engineering, ASCE, 1989, Vol. 115, pp. 1525-1537.

[7] Kayser, J.R., "The Effects of Corrosion on the Reliability of Steel Girder Bridges”, PhD thesis, Department of Civil Engineering, University of Michigan, USA, 1988.

[8] Albrecht, P. and Naeemi, A.H., "Performance of Weathering Steel in Bridges", National Cooperative Highway Research Program, Report 272, Transportation Research Board, National Research Council, Washington, D. C., 1984.

[9] Rahgozar, R., "Remaining Capacity Assessment of Corrosion Damaged Beams using Minimum Curves”, Journal of Constructional Steel Research, Elsevier, 2009, Vol. 65, pp. 299-307.

[10] Rahgozar, R., "Fatigue Endurance of Steel Structures Subjected to Corrosion”, PhD. Thesis, Department of Civil Engineering, University of Bristol, UK, 1998.

[11] Sharifi, Y. and Rahgozar, R., "Simple Model to Estimate the Remaining Moment Capacity of Corroded Varying Thickness Loss of I-Beam Sections", Proceeding of the $11^{\text {th }}$ National Corrosion Congress, Kerman, Iran, 2009, pp. 1237-1244.

[12] Nethercot, D.A., "Limit States Design of Structural Steelwork”, Third Edition, Spon Press, London, UK, 2001.

[13] Fontana, M.G., “Corrosion Engineering”, McGraw Hill Book Company, New York, Third Edition, 1987.

[14] Kayser, J.R. and Nowak, A.S., "Evaluation of Corroded Steel Bridges”, Proceedings of Structures Congress Related to Bridge and Transmission Line Structures, American Society of Civil Engineers, Orlando, Florida; 1987, pp. 35-47.

[15] Trahair, N.S., Bradford, M.A. and Nethercot D.A, "The Behavior and Design of Steel Structures to BS5950”, Third Edition, British, London, Spon Press, Taylor \& Francis Group, 2001.

[16] Timoshenko, S.P. and Gere, J.M., “Theory of Elastic Stability”, McGraw-Hill Book Company, 1961.

[17] Stowell, E.Z., Heimerl, G.J., Libove, C. and Lundquist E.E., "Buckling Stresses for Flat Plates and Sections”, Transaction of ASCE, 1952, Vol. 117, pp. 545-578.

[18] Johnston, B.G., "Guide to Stability Design Criteria for Metal Structures”, Third Edition, John Wiley \& Sons, 1976.

[19] BS 5950, "Structural use of Steel Work in Building: Part 1, Code of Practice for Design in Simple and Continuous Construction, Hot Rolled Sections”, British Standard Institution, London, 1985.

[20] Horne, M.R., "Plastic Theory of Structure”, Thomas Melson and Sons, Ltd, 1971. 